\title{
Inquiry-Based Learning in Sports/the Movement Sciences
}

\author{
Felix Riehl, Anna Dannemann, Robert Zetzsche, \\ and Christian Maiwald
}

\subsection{Characteristic Features in the Movement Sciences}

The characteristic features of the discipline are placed prominently within the context of implementing inquiry-based learning in the modules for the sports and movement sciences degree program at the Chemnitz University of Technology.

\subsubsection{Subject and Fields of Application}

The movement sciences are characterized as a cross-sectional science, the content of which is the study of sports and movement from the perspective of various departments. With reference to the parent disciplines, the movement sciences and sports science are subdivided into areas belonging to the medical natural sciences, the liberal arts/pedagogy, and the social sciences (cf. Krüger \& Emrich 2013, p. 18). The varied perspectives go hand in hand with a strong differentiation of the sports science degree programs. In addition to

F. Riehl, M.Sc. $(\bowtie) \cdot$ A. Dannemann, M.Sc. · R. Zetzsche, Dipl.-Soziologe Technische Universität Chemnitz, Fakultät für Human- und Sozialwissenschaften, Institut für Angewandte Bewegungswissenschaften, Chemnitz, Germany e-mail: felix.riehl@hsw.tu-chemnitz.de; anna.dannemann@hsw.tu-chemnitz.de; robert.zetzsche@hsw.tu-chemnitz.de

C. Maiwald, Prof. Dr. rer. nat.

Professur für Forschungsmethoden und Analyseverfahren in der Biomechanik, Technische Universität Chemnitz, Fakultät für Human- und Sozialwissenschaften, Institut für Angewandte Bewegungswissenschaften, Juniorprofessur Forschungsmethoden und Analyseverfahren, Chemnitz, Germany e-mail: christian.maiwald@hsw.tu-chemnitz.de 
an engagement with various sub-disciplines, the active and reflective engagement with different sports is part of the degree program (cf. Burk and Fahrner 2013, pp. 11-13). Due to this diversification, the labor market for students in sports science and the movement sciences is very heterogeneous. In addition to the school-related area, there are a variety of areas of activity in the extra-curricular labor market, such as the prevention and rehabilitation sector, recreational and competitive sports, sports economics, journalism and science (cf. Krüger and Emrich 2013, pp. 48-51).

A course of study in the movement sciences at Chemnitz University of Technology provides a broad range of topics in the field of sports and physical activity within its fundamentals. The focus is in the area of prevention and therapy, in which the majority of graduates later find their careers. The diverse contents in the relatively short training period are increasingly practice-oriented and have become more strongly focused on employability within the context of Bologna (cf. Spoun 2007, p. 47). In addition to specialist knowledge, the social and personal competencies which are needed in dealing with students, athletes, and patients play an important role (cf. Reiber 2010, pp. 18-20).

\subsubsection{Problem and Selecting a Teaching Concept}

An interest in deeper engagement with research and scholarship is not a priority for most students of movement sciences, as only a small proportion of graduates will work in the professional field within higher education and research and development. However, engagement with these subject areas is essential for critically addressing the knowledge acquired in cooperating departments before that knowledge is implemented into the practice of training and rehabilitation. In addition to the promotion of skills and the acquisition of expertise, the goal is to achieve transparency in the generation of knowledge in the sense of scientific work. In so doing, science should be made tangible as a process and be classified within a disciplinary context (cf. Huber 2009, pp. 13-14).

Students have their first contact with content relating to research methodology in the bachelor's degree program at Chemnitz University of Technology through their autonomous participation in a research project, as well as their first project within the context of their bachelor thesis. Methodological and statistical training and the imparting of epistemological knowledge is deepened over the course of the consecutive master's degree program.

Generating methodological knowledge within the context of sports science and the movement sciences represents a challenge when selecting a suitable teaching concept, which should take into account the range of subjects and their various perspectives and approaches, as well as enable students to set their own individual priorities. A traditional teaching concept appears to be less suitable for this. A comprehensive educational ideal such as that of inquiry-based learning, which goes beyond the teaching of subject-related competencies, is increasingly invoked as a maxim for the study. Here, learning is 
understood as a way of life and students are sensitized to question knowledge, beliefs and presuppositions (cf. Spoun 2007, p. 47).

\subsection{Inquiry-Based Learning in the Movement Sciences}

The motivations and the understanding of inquiry-based learning as a basis for teachinglearning concepts in the movement sciences are based on developments in research, teaching and higher education didactics. This serves as a starting point for considering existing modules and forms the basis for planning and implementing the "Wissenschaftstheorie und Forschungsmethodik" ("Philosophy of science and research methodology") course. This enables students to acquire some initial experience with implementing scientific thinking and research methodologies, and to identify specific challenges for future projects.

\subsubsection{Research, Teaching, and Developments in Higher Education Didactics}

The challenges of teaching methodological knowledge in sports science and the movement sciences are shaped by the Bologna Process, developments in teaching and learning research, and the discourse between teaching and research.

Fundamental changes of perspective in higher education didactics and teachinglearning research has resulted in a variety of models and concepts so that appealing teaching can be implemented at universities. As such, the focus has been increasingly shifted from input to the outcome of teaching, and oriented towards learning and learners. Ultimately, our understanding of the task of a higher education didactic expert has also changed from imparting knowledge to advising and supporting (cf. Schaeper 2008, pp. 197-199; Reiber 2006, pp. 6-9). These changes are based on a constructivist understanding of general didactics, in which learning is seen as an individual act of creating knowledge, skills, and competencies. This takes place in concrete situations and therefore, in addition to the learning topic, requires communicative interaction, a corresponding social form, and the embedding of media and methods (cf. Jank and Meyer 2014, pp. 286-303).

\subsubsection{Fundamentals and Application of Inquiry-Based Learning}

Within the context of higher education and taking into account changes within teaching/ learning research, inquiry-based learning provides a versatile opportunity for teaching methodological knowledge in the field of movement sciences. According to the following features and integration possibilities described by Huber (2009), inquiry-based learning is 
oriented towards the phases of independently conducting a research project and the resulting cognitive, emotional, and social experiences. Essential features that distinguish inquiry-based learning from similar teaching concepts such as a student-centered structure, independent study, discovery and problem-based learning, or project-based studies, are the central facet of gaining new insights, as well as the social aspect of a "scientific community." The resulting teaching-learning concept can be integrated into the format of higher education instruction by having students take part in concrete situations and case studies, work on new problems, work-shadowing and participation in research laboratories and business simulations, and through their own studies.

At the Chemnitz University of Technology, opportunities for autonomous participation in research projects, in the form of research laboratories and processing simulated planning games, already exist within the context of the degree program in the movement sciences. Here, students from various departments gain insights into the concrete planning, conducting, and implementation of research projects. In the bachelor's degree program, it is possible to select from a variety of existing projects in different departments. Selecting from among the available projects is obligatory and an integral part of a module in the study regulations. The chosen project is then actively supported by the participants and terminates with a final report, which is a conducive contribution for the project leader in the evaluation and further processing of the research project. Thus, students have the opportunity to be introduced to specific elements of research at an early stage in a subject area of their choice. Examples include a sports medicine project for recording children's motor performance, or a sports education project for the temporal development of children's motor skills.

In sports science and the movement sciences, the "Wissenschaftstheorie und Forschungsmethodik" ("Philosophy of science and research methodology") course in the master's degree program is a focal point in implementing inquiry-based learning. Methodical and epistemological material is specifically addressed and transmitted over two semesters as part of an independently conducted research project. This represents the most extensive wealth of experience in the movement sciences within the context of inquiry-based learning and will therefore be described and explained in detail below.

\subsubsection{Implementing and Evaluating the "Wissenschaftstheorie und Forschungsmethodik" ("Philosophy of Science and Research Methodology") Module}

The various integration possibilities of inquiry-based learning are based on the general cycles of research activity and learning. The starting point comprises the basic phases of identifying a topic, formulating questions and hypotheses, creating a research design; and implementing and evaluating, as well as imparting, applying, and putting into practice. The research cycles overlap with the basic learning processes of experience, reflection, conception and experimentation (cf. Wildt 2009, pp. 5-6). 


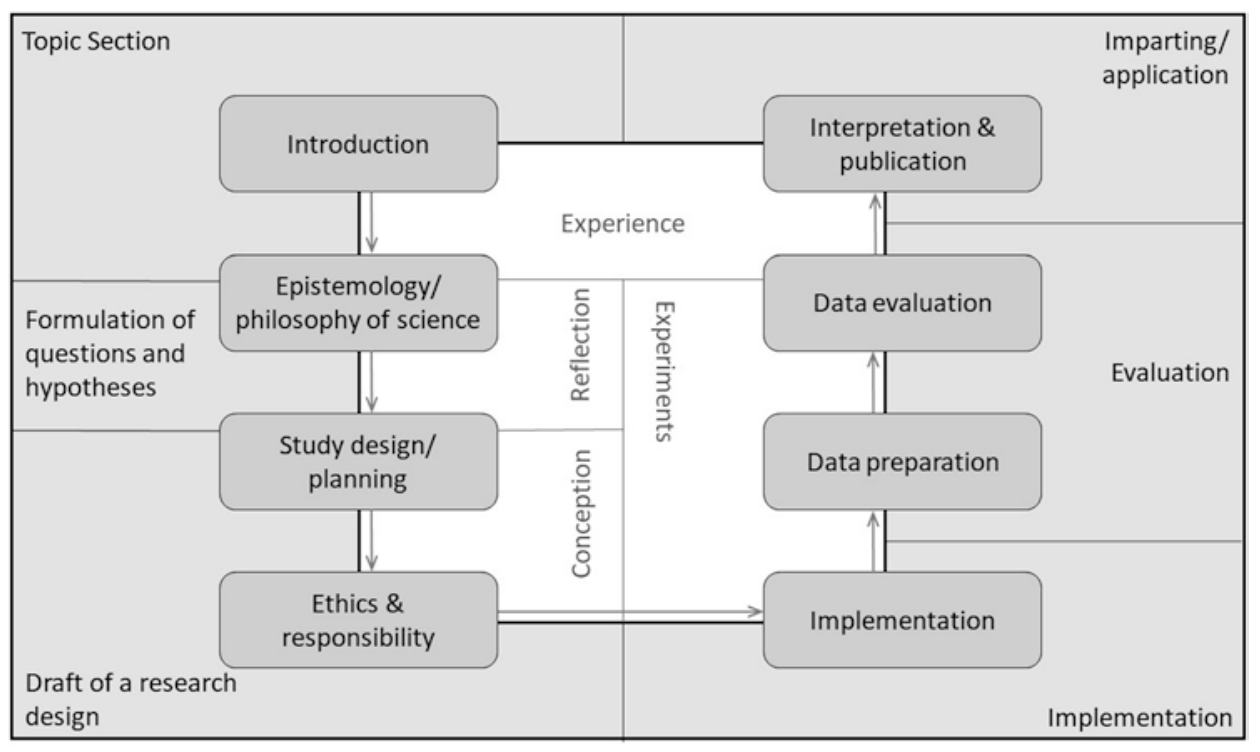

Fig. 30.1 Progression of the philosophy of science and research methodology module at TU Chemnitz in relation to the cycles of inquiry-based learning. (Source: Author's representation, modified in accordance with Wildt 2009)

After an introductory and informational event, the module which is implemented in the master's degree program at the Chemnitz University of Technology (see Fig. 30.1) begins with the topic and group identification phase. During this first section of the module, students are given a general orientation about the progression of the course and the opportunity to increasingly deal with their own research interests. After these initial experiences, the students find themselves in small research groups that persist throughout the module.

The subsequent phase involves deeper engagement with theory and the development of hypotheses. Here, groups of 4-5 students work independently and autonomously to engage with the theoretical status of their chosen research concerns. During this time, the lecturers and tutors are available to advise and assist in formulating a concrete question. At the same time, the students gain a theoretical insight into cognitive science and the philosophy of science.

The preparation and presentation of concrete research ideas and hypotheses is followed by a phase during which students elaborate on a suitable study design. In this section, the small groups receive a theoretical refresher on the planning and design of studies while they develop appropriate sequences of actions, tools and procedures for their own research project. The results of this and the previous phases are put forth in a presentation and a summary project proposal.

Ethical aspects are examined and an internal ethics committee is convened before data collection can occur. Here, the students are sensitized at a theoretical level to issues of responsible science and implement the knowledge they acquire in formulating an ethics 
proposal. Together with the lecturers and tutors, the small groups subsequently assess the ethical safety of the projects of the other research groups in an internal ethics committee. The implementation and survey phase takes place between the two semesters of the module and represents a transition between research planning and data analysis. In this phase, students are largely independent in terms of organization and implementation. The lecturers once again assume a supporting and accompanying role to ensure the goal of having completed data entry at the beginning of the new semester.

In the second semester, students run through various options for statistical evaluation and drawing a conclusion in alternation at a theoretical and applied level in the form of a lecture and tutorial. Within this context, students deal with descriptive and inductive statistics, as well as the transfer of findings to their own research project. This section, which represents the end of the entire research cycle, concludes with the small groups writing a scholarly article. Here, the preparatory work from the first semester and the evaluation from the second semester in the "Wissenschaftstheorie und Forschungsmethodik" ("Philosophy of science und research methodology") modules merge together and ideally lead to new findings.

According to David Kolb, another framework for planning and implementing inquirybased learning is based on the four elementary learning processes of experience, reflection, conception and experimentation (cf. Staemmler 2006, pp. 46-50). In the progression of the module depicted here, it is initially assumed that students in the master's degree program have substantial theoretical and methodological experience. Students' engagement with various subject-related perspectives and topic areas, as well as the comprehensive, research-methodological consideration of the findings, forms the basis for topic identification in their own research projects. Reflection on one's own experience is necessary to identify existing inconsistencies or unresolved issues, which should enable a unique research question to be formulated. The following elements of research planning and research design can be summarized under the process of learning how to engage in conceptive processes. In doing so, the students are expected to engage in active and creative activities. By contrast, the data collection phases have an experimental character. Finally, the experiences and insights gained from the entire process form the basis for new research projects and are formally presented in the scientific article. The contents and methods of the individual phases of the module fulfill the competence requirements of sports and movement scientists on the job market to a large extent.

\subsubsection{Support, Test Performances, and Formats}

As students go through each section of the module, they receive support from the respective lecturers, tutors, and specific feedback from students in other research groups. This ensures that their own research process is reflected from different perspectives within the context of situational learning, and that it recreates the atmosphere of a scientific community. Here, participants receive the theoretical background for, and feedback on, the 
preliminary examinations from the lecturers. This enables the students to provide their content with an orientation and, ultimately, to assess what is and is not possible within their own research project.

It is a clear advantage that the tutors providing support have already completed this or a similar teaching-learning arrangements. Each tutor is responsible for two to three groups, supports the preparation of content-related aspects and is available for questions regarding the working method and group conflicts that arise. A special feature of this form of support lies in the relationship between the tutors and students, which is on an equal-terms basis, and in the function of imparting knowledge between participants and lecturers.

Another level of support is mutual feedback from the individual research groups. The results of the various sections and sub-points of the research cycle are loaded into a digital portal and can be viewed there by the other students. Using a fixed matrix, two to three research groups generate feedback in the form of peer reviews for the respective group. Thus participants receive feedback, again on equal terms, and in the form of a scientific community. The advantage of this is that the small groups deal with both the content and methodological aspects of others and that constructive criticism is likely to be more readily accepted and implemented.

As already indicated, students in the individual research groups have a variety of preparatory work and examinations. Fourteen smaller preliminary examinations (e.g. a short essay on the topic of "What is science?", presentation of the research question, written submission of a project proposal, or presentation of the descriptive evaluation) are integrated into the cycle for the entire module. The elements of the three central exams are the reproduction of knowledge via cognitive science and philosophy of science, an applicationoriented exam on research methodology and statistics, and the final textualization of the research process and outcome in the form of an article. The aim of including such diverse forms of examination and focus is to meet the needs of different types of learning and different career models. Here, there is a relationship to a large percentage of the work areas of sports and exercise therapists; these also pose a variety of challenges in everyday work, for example in working with patients and with children and youth. An additional focus in designing the teaching-learning concept for inquiry-based learning in the movement sciences degree program is on the number and manifestation of the exam prerequisites. This again aligns with the practical conditions in the work performed as a therapist and trainer, who rarely have exceptional one-time achievements, but who instead tend to guide a process with multiple intermediate outcomes. Even if individual advance performances are still occurring at the beginning of the research cycle, they will only be completed in the following phases exclusively in the research groups. At the content level, forms of scientific communication are required, such as presentations, essays, contributions to discussions and applications.

The topic of research methodology and philosophy of science, which was originally an abstract concept, is not only considered and questioned in a variety of forms, it also receives a concretely applied and technical perspective by means of the individual issues of the research groups. Thus, a variety of topics, ranging from university sports at 
universities in Saxony to the consideration of myofascial taping to the effect of cloth baby slings on the musculoskeletal system, thus meets the general and theoretical perspective of the philosophy of science and research methodology. This effects that subject-specific topics are considered critically, and that topics which are increasingly perceived as isolated are revived. In this way, an effort is made to establish the aforementioned bridge between practical and subject-specific requirements and methodological reflection.

In summary, higher education instruction and the "Wissenschaftstheorie und Forschungsmethodik" ("Philosophy of science and research methodology") module have incorporated a variety of content and methodological aspects into teaching and learning planning. The planning and implementation of the individual elements took place with the inclusion of new perspectives in higher education didactics and within the concept of inquiry-based learning. As such, the two basic research and learning cycles constitute guidelines for designing the module.

\subsection{Challenges and Outlook}

In recent years, students have conducted 23 research projects within the context of the course (last updated: December 2015). In so doing, both instructors and supervising faculty were able to gather many impressions and obtain much feedback, and students were given the opportunity to present their perceptions and perspectives within the framework of assuring the quality of the teaching, and by means of formal evaluation.

\subsubsection{Evaluation of the "Philosophy of Science and Research Methodology" Module ("Wissenschaftstheorie und Forschungsmethodik")}

The informal impressions of the instructors and supervising faculty point to a positive overall picture of the teaching-learning arrangement used for inquiry-based learning in the movement sciences. Numerous students have given positive feedback regarding the longterm collection and retention of acquired knowledge, and noted a perceived increase in methodological, social and personal competencies. The high-performance groups in particular found the constant challenge of meeting fixed deadlines and constantly being challenged a profitable experience for their future professional lives. The group work was primarily described as pleasant and supportive, and many students found the support and encouragement they received from various people and contact persons to be helpful.

These experiences and impressions were also reflected in formal evaluation by the students, which were conducted at the end of each semester as part of the quality assurance for the course. The majority of the participants were able to develop an understanding of science and empirical research. In addition, a large proportion of students reported having developed a fundamental interest in research within the context of increasingly nonscientific professional fields in the labor market for sports and exercise scientists. 
While working on a project with a variety of intermediate performances, it became apparent that motivation dropped significantly at the end of each semester and less work was done on preliminary examinations. Another challenge was the familiarization with various topics, due to the heterogeneity of the degree program. Formulating constructive and responsive feedback requires attempting to understand new fields and applying knowledge that has already been acquired. The requirement to critically reflect on research projects and on questions of logic, statistics and the philosophy of science on abstract levels was a challenge, but was successfully mastered in the overall picture of the module. Participants in the module as well as the lecturers and tutors faced a variety of challenges in implementing the teaching-learning module of inquiry-based learning. Most experiences coincide with the problem areas and critical points of inquiry-based learning according to Huber (2009, pp. 22-28).

\subsection{Conclusion for TU Chemnitz and Sports Science in General}

In the future, the module needs to be designed and implemented more efficiently and in a way that conserves resources. This could be achieved, for example, by incorporating the online learning platform to a greater to degree, increasing automation of open processes (e.g. through templates and automatic evaluation processes) or restricting the selection of research projects.

This educational ideal can be used in sport science and the movement sciences to implement a promising instrument so that it is possible to take abstract topics like method teaching and the variety of subject areas in the study program into account. The active and creative participation of the students makes it possible to generate positive effects on attitude and interest towards abstract and complex topics such as research methodology and philosophy of science. Moreover, this can be used to ensure the transfer of competencies required by companies and within the framework of the Bologna Process. Addressing these issues by linking subject-oriented and non-subject-oriented competencies in a complex learning environment is one of the key benefits of inquiry-based learning. Moreover, the conception and implementation of this educational ideal within the framework of movement sciences must always take into account both conditions and resources. Furthermore, an active evaluation of the processes is considered necessary. Just as movement sciences are in the process of development, a great deal of movement is also expected in the implementation and design of inquiry-based learning.

\section{References}

Burk, V./Fahrner, M. (2013). Einführung in die Sportwissenschaft. Konstanz: UVK Verlagsgesellschaft mbh.

Huber, L. (2009). Warum Forschendes Lernen nötig und möglich ist. In L. Huber/J. Hellmer/F. Schneider (Hrsg.), Forschendes Lernen im Studium. Aktuelle Konzepte und Erfahrungen (S. 9-35). Bielefeld: UniversitätsVerlagWebler. 
Jank, W./Meyer, H. (2014). Didaktische Modelle. Berlin: Cornelsen.

Krüger, M./Emrich, E. (2013). Die Wissenschaft vom Sport. In A. Güllich/M. Krüger (Hrsg.), Sport. Das Lehrbuch für das Sportstudium (S. 10-23). Berlin: Springer Spektrum.

Reiber, K. (2006). Wissen - Können - Handeln: Ein Kompetenzmodell für lernorientiertes Lernen. In C. Baatz/R. Richter (Hrsg.), Tübinger Beiträge zur Hochschuldidaktik. (2. Auflage) (S. 6-9). Tübingen: Arbeitsstelle Hochschuldidaktik.

Reiber, K. (2010). Kompetenzentwicklung durch forschendes Lernen in pflege- und gesundheitsbezogenen Studiengängen. In A. Nauerth (Hrsg.), Hochschuldidaktik in pflegerischen und therapeutischen Studiengängen (S. 17-27). Münster: LIT.

Schaeper, H. (2008). Lehr-/Lernkulturen und Kompetenzentwicklung: Was Studierende lernen, wie Lehrende lernen und wie beides miteinander zusammenhängt. In K. Zimmermann/M. Kamphans/S. Metz-Göckel (Hrsg.), Perspektiven der Hochschulforschung (S. 197-199). Wiesbaden: Verlag für Sozialwissenschaften.

Spoun, S. (2007). Ein Studium für's Leben. Das Hochschulwesen, 55 (2), 46-53.

Staemmler, D. (2006). Lernstile und interaktive Lernprogramme. Kognitive Komponenten des Lernerfolgs in virtuellen Lernumgebungen. Wiesbaden: Deutscher Universitäts-Verlag.

Wildt, J. (2009). Forschendes Lernen: Lernen im »Format «derForschung. Journal Hochschuldidaktik, $20,4-5$.

Open Access This chapter is licensed under the terms of the Creative Commons AttributionNonCommercial-NoDerivatives 4.0 International License (http://creativecommons.org/licenses/bync-nd/4.0/), which permits any noncommercial use, sharing, distribution and reproduction in any medium or format, as long as you give appropriate credit to the original author(s) and the source, provide a link to the Creative Commons licence and indicate if you modified the licensed material. You do not have permission under this license to share adapted material derived from this chapter or parts of it.

The images or other third party material in this chapter are included in the chapter's Creative Commons licence, unless indicated otherwise in a credit line to the material. If material is not included in the chapter's Creative Commons licence and your intended use is not permitted by statutory regulation or exceeds the permitted use, you will need to obtain permission directly from the copyright holder.

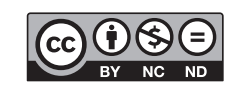

